\title{
Adaptação de um equipamento para ensaios de desgaste de materiais cerâmicos
}

\section{(Experimental setup for wear testing of ceramic materials)}

\author{
R. F. de L. Lorenzi, C. A. Perottoni, J. E. Zorzi \\ Laboratório de Materiais Cerâmicos, Universidade de Caxias do Sul, Caxias do Sul, RS 95070-560 \\ jezorzi@ucs.br
}

\begin{abstract}
Resumo
É descrita em detalhes a montagem de um equipamento simples e de baixo custo para a medida da resistência ao desgaste de materiais cerâmicos. Para demonstrar a aplicação deste equipamento foram realizadas medidas de desgaste em amostras de alumina e zircônia parcialmente estabilizada com ítria. A resistência ao desgaste das amostras de zircônia foi medida antes e depois da formação de um recobrimento de $\mathrm{ZrC}$, mediante tratamento térmico a $1600{ }^{\circ} \mathrm{C}$, com a peça envolta por carbono, em atmosfera de argônio. Foi observado que a formação de $\mathrm{ZrC}$ proporciona uma resistência ao desgaste similar à da alumina, aproximadamente $50 \%$ superior à da zircônia.
\end{abstract}

Palavras-chave: coeficiente de desgaste, alumina, zircônia, $\mathrm{ZrC}$.

\begin{abstract}
The assembly of a simple, low cost equipment for the measurement of the wear coefficient of ceramic materials is described in some detail. This equipment was applied to the determination of the wear coefficient of alumina and yttria-partially stabilized zirconia. The wear resistance of zirconia was measured before and after the formation of a ZrC coating on the surface, as the result of a thermal treatment at $1600{ }^{\circ} \mathrm{C}$ with the sample wrapped in a carbon powder bed in an argon atmosphere. It was observed that the formation of $\mathrm{ZrC}$ provides a surface wear resistance similar to that obtained for alumina, almost 50\% higher than that of bulk zirconia.
\end{abstract}

Keywords: wear coefficient, alumina, zirconia, $\operatorname{ZrC}$.

\section{INTRODUÇÃO}

A técnica de microabrasão é comumente empregada para a determinação da espessura de filmes depositados sobre a superfície de materiais. Seu princípio de funcionamento é simples: uma esfera de aço endurecido é apoiada ao mesmo tempo sobre a superfície da amostra e sobre uma depressão de um eixo ligado a um motor elétrico. Durante o ensaio, o eixo gira a esfera atritando-a contra a superfície da amostra ao mesmo tempo em que um líquido abrasivo é gotejado sobre a esfera. Este processo promove o desgaste do material da superfície da amostra, formando duas crateras concêntricas, uma devido ao filme e a outra devido ao substrato [1]. A espessura do filme depositado $(t)$ é dada por $t=X Y / 2 R$, onde $R$ é o raio da esfera e $X$ e $Y$ são dimensões exibidas na Fig. 1.

Se o material desgastado não possui uma camada depositada, o resultado será a formação de uma única cratera, cujo diâmetro é medido por microscopia óptica. A partir deste diâmetro, pode se calcular o coeficiente de desgaste, $K$, a partir da relação [2-4]

$$
\mathrm{K}=\frac{\pi \mathrm{b}^{4}}{64 \mathrm{R} \mathrm{L} \mathrm{F}_{\mathrm{N}}}
$$

onde $L$ é a distância percorrida pela esfera sobre a amostra,
$F_{N}$ é a força normal sobre a esfera, $b$ é o diâmetro da cratera formada e $R$ é o raio da esfera. Em ensaios de desgaste de materiais recobertos com filmes finos, são observadas duas

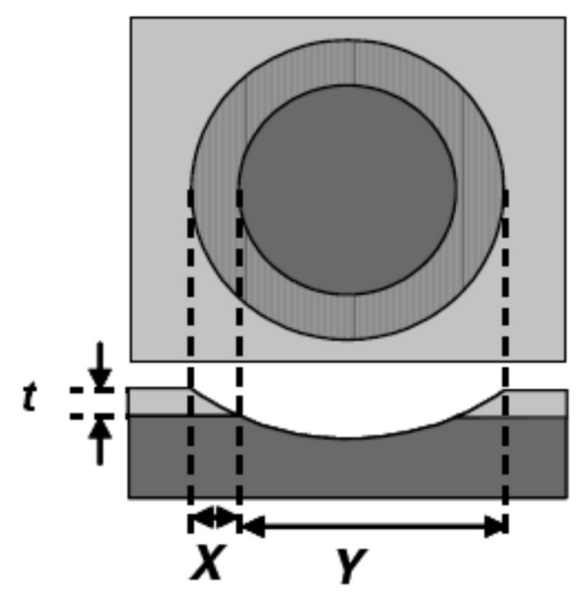

Figura 1: Representação esquemática de duas crateras concêntricas e das medidas necessárias para a determinação da espessura do recobrimento. Adaptada [8].

[Figure 1: Schematic representation of two concentric wear craters and the dimensions needed for the determination of film thickness. Adapted [8].] 
crateras concêntricas (filme e substrato), a partir das quais se calcula a espessura do filme depositado e o coeficiente dedesgaste do filme $\left(K_{c}\right)$ e do substrato $\left(K_{s}\right)$, pela análise dos dados em um gráfico de $\left(L F_{N} / b^{4}\right)$ versus $\left(\pi t / 4 b^{2}-\pi R t^{2} / b^{4}\right)$ [3-7]. $\mathrm{O}$ número mínimo recomendado de crateras em cada ensaio é seis, o diâmetro interno mínimo é dado por $\left(8 R d_{1}\right)^{0,5}$, onde $d_{1}$ é o diâmetro do abrasivo, e o diâmetro externo máximo é da ordem de 1,6 mm (para uma esfera com raio de 12,5 mm) [5]. Conforme a equação A, para a determinação do coeficiente de desgaste por microabrasão é necessário que o equipamento tenha uma célula de carga para a determinação da força normal que age sobre a esfera de metal (Fig. 2) [2].

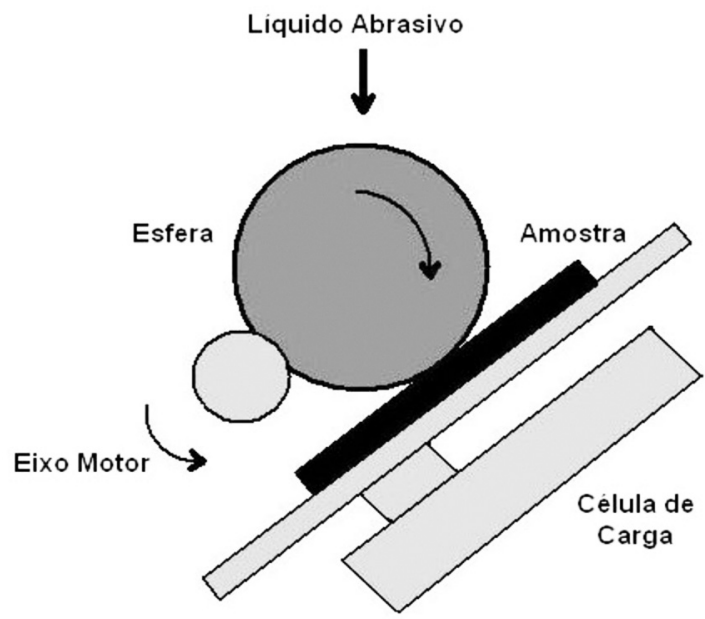

Figura 2: Esquema de funcionamento do equipamento para ensaio de microabrasão. Adaptado [9].

[Figure 2: Schematic representation of the microabrasion tester equipment. Adapted [9].]

Neste trabalho, um equipamento usado na determinação da espessura de filmes foi adaptado para a realização de estudos de desgaste em materiais cerâmicos. Este equipamento foi empregado na determinação da resistência ao desgaste de amostras de alumina e zircônia parcialmente estabilizada e, também, de uma amostra da mesma zircônia carbonetada termicamente a $1600{ }^{\circ} \mathrm{C}$ em atmosfera de argônio.

\section{MATERIAIS E MÉTODOS}

A amostra de alumina usada neste trabalho foi obtida a partir do pó Martoxid MR70/S (Martinswerk). A zircônia utilizada foi TZ-3YB (parcialmente estabilizada com 3\% em mol de ítria $\left(\mathrm{Y}_{2} \mathrm{O}_{3}\right)$, Tosoh). Ambos pós cerâmicos são comerciais e já possuem ligantes próprios para prensagem. As amostras foram conformadas por prensagem uniaxial (1 kbar) em um molde metálico (discos com $10 \mathrm{~mm}$ de diâmetro e $2 \mathrm{~mm}$ de espessura) e sinterizadas a $1600{ }^{\circ} \mathrm{C} / 2 \mathrm{~h}$ (alumina) e $1500^{\circ} \mathrm{C} / 2 \mathrm{~h}$ (zircônia) ao ar, com rampa de aquecimento 1 ${ }^{\circ} \mathrm{C} / \mathrm{min}$. Após a sinterização, uma amostra de zircônia foi submetida a tratamento térmico em leito de pó de carbono amorfo (Printex, Degussa) a $1600{ }^{\circ} \mathrm{C}$ em um forno com resistências de grafite em atmosfera de argônio (Thermal
Inc.) por $3 \mathrm{~h}$. As amostras de alumina e a de zircônia parcialmente estabilizada com ítria (3Y-PSZ) foram polidas com pastas diamantadas até $1 \mu \mathrm{m}$. A amostra de zircônia tratada termicamente não foi polida para preservar a camada carbonetada.

\section{Equipamento para a determinação do coeficiente de desgaste}

Para a análise da resistência ao desgaste, primeiramente necessitamos conhecer a força normal que a superfície do material exerce sobre a esfera. Para isso foi adquirida uma célula de carga HBM (Weightech) PW4MC3 com capacidade $500 \mathrm{~g}$ e sensibilidade $1 \mathrm{mV} / \mathrm{V}$ [8]. Foi montado um circuito para amplificar o sinal de saída da célula de carga, utilizando para isso um CI amplificador para instrumentação INA125P (Fig. 3) [9]. Além do CI, complementam o circuito eletrônico uma fonte de computador para alimentação do circuito, um potenciômetro $\mathrm{P}$ para ajuste do zero e um transistor TIP29C para a alimentação da ponte de Wheatstone da célula de carga. O ganho do amplificador é alterado no resistor variável $R_{G}$. Um multímetro exibe a tensão oriunda do desbalanceamento da ponte de Wheatstone da célula de carga, que é proporcional à força que age sobre ela. Também foi adquirida uma bomba peristáltica (Provitec DM AXD) [10] para gotejar controladamente a suspensão abrasiva sobre a esfera rolante e um agitador magnético (VELP) para manter em constante agitação a suspensão abrasiva. A Fig. 4 ilustra a montagem final do equipamento. Na Fig. 5 pode-se

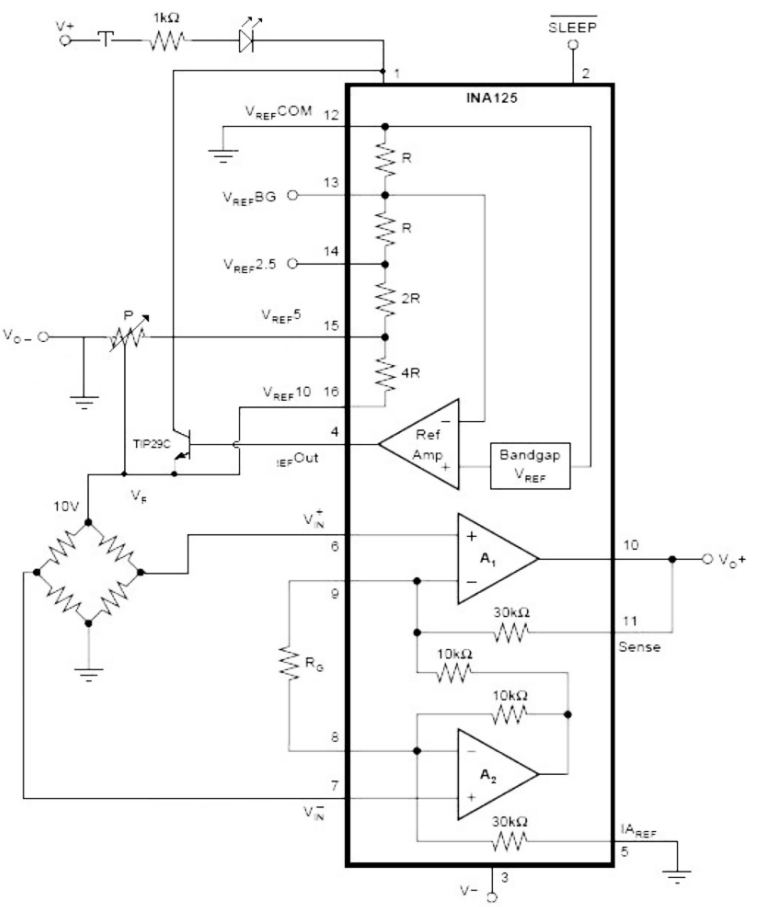

Figura 3: Diagrama do circuito de alimentação e amplificação do sinal da célula de carga. A tensão de saída é lida entre $\mathrm{Vo}^{-}$e $\mathrm{Vo}^{+}$. Adaptado [11].

[Figure 3: Electric diagram of the source and amplifying circuit for the load cell. The output signal is measured between $\mathrm{Vo}^{-}$and $\mathrm{Vo}^{+}$. Adapted [11].] 


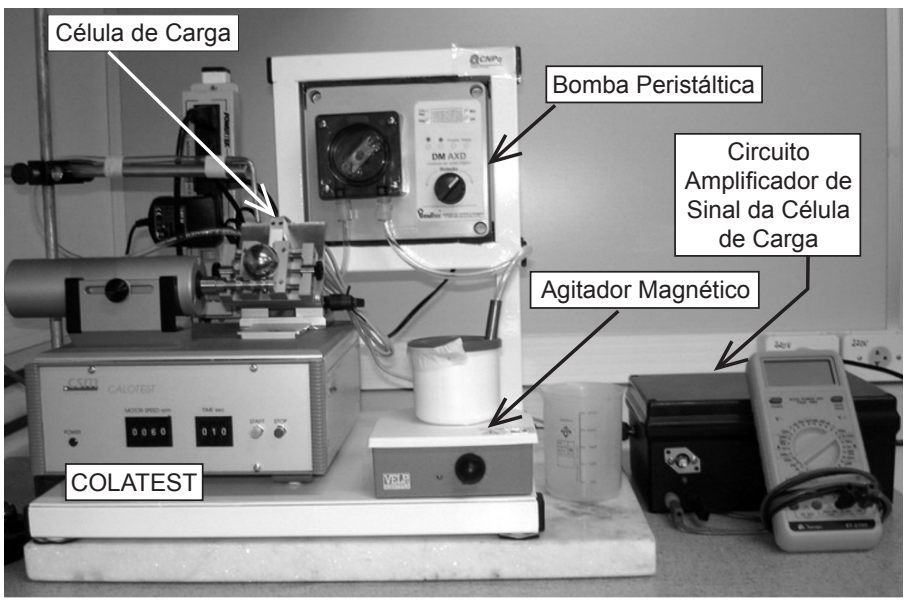

Figura 4: Montagem experimental usada na determinação do coeficiente de desgaste de materiais cerâmicos.

[Figure 4: Experimental setup for the measurement of the wear coefficient of ceramic materials.]

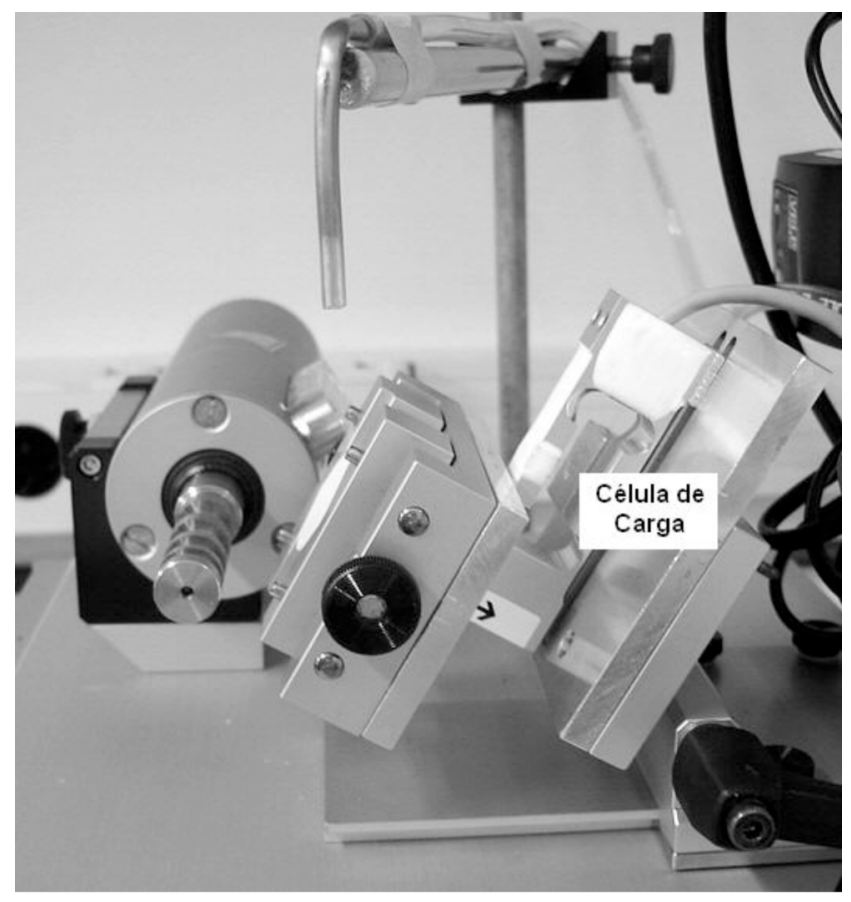

Figura 5: Detalhe do porta-amostra com a célula de carga. [Figure 5: Detail of the sample holder with load cell.]

ver em detalhe a fixação do suporte para a amostra sobre a célula de carga.

A célula de carga foi calibrada usando esferas de aço de diferentes massas. O peso de cada uma destas esferas foi calculado utilizando o valor da aceleração da gravidade obtido a partir da expressão

$$
\begin{aligned}
& \mathrm{g}\left(\mathrm{m} / \mathrm{s}^{2}\right)=9,780356\left(1+0,0052885 \operatorname{sen}^{2} \theta-\right. \\
& \left.0,0000059 \operatorname{sen}^{2} \theta\right)-00,003086 H
\end{aligned}
$$

na qual $g$ é a aceleração da gravidade, $H$ é a altitude $(\mathrm{km})$ e $\theta$ é latitude [11]. A aceleração da gravidade calculada para Caxias do Sul é $9,763 \mathrm{~m} / \mathrm{s}^{2}$. A Fig. 6 exibe a curva de calibração obtida para a célula de carga, $F_{N}=0,0131(2) V, V$ é tensão $(\mathrm{mV})$ e $F_{N}$ é a força normal $(\mathrm{N})$.

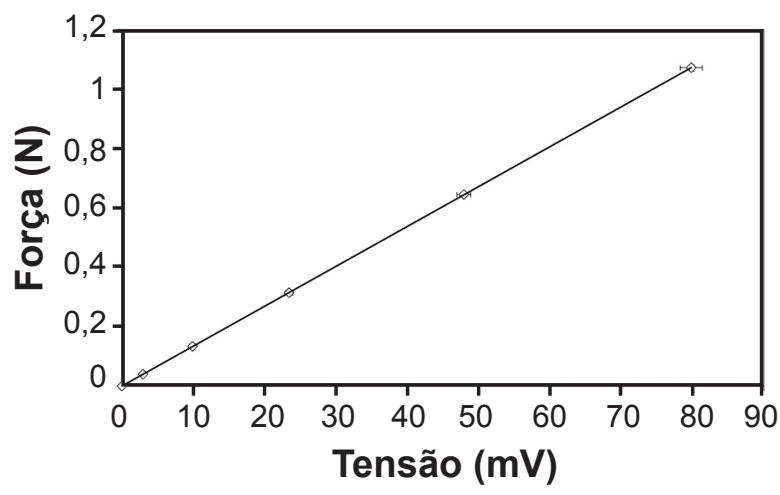

Figura 6: Curva de calibração da célula de carga.

[Figure 6: Calibration data of the load cell.]

Após a amostra ser fixada no porta-amostra, o multímetro indicador da força normal é zerado e uma esfera de aço é apoiada sobre a amostra e o eixo do motor. Em seguida, a bomba peristáltica é ligada e a suspensão abrasiva começa a gotejar sobre a esfera. Uma suspensão abrasiva de base aquosa com partículas de diamante com diâmetros que variam de 0,5 a $1 \mu \mathrm{m}$ foi utilizada durante os ensaios de desgaste. O tempo de ensaio e a velocidade de rotação do eixo são ajustados e, então, realiza-se o ensaio.

Medida das crateras e cálculo do coeficiente de desgaste

O movimento da esfera sobre a superfície da amostra promove a formação de uma cratera de desgaste cujo diâmetro depende da resistência ao desgaste do material e das condições do ensaio. O diâmetro destas crateras é determinado com o auxílio de um microscópio óptico e um programa de aquisição e análise de imagens.

O coeficiente de desgaste de um material é obtido a partir da declividade da reta ajustada aos dados experimentais em um gráfico de $\left(\pi b^{4} / 64 F_{N} R\right)$ versus $(L)$. A distância percorrida pela esfera sobre a amostra, $L$, é obtida de [2-4]

$$
\mathrm{L}=\frac{\pi \mathrm{R}^{\prime} \mathrm{Nd}}{\sqrt{\frac{\mathrm{d}^{2}}{4}-\mathrm{R}^{\prime \prime 2}}}
$$

onde $N$ representa o número de voltas dadas durante o ensaio pelo eixo que sustenta a esfera, $R$ ' é o raio de giro do eixo, $d$ é o diâmetro da esfera e $R$ "é a metade da largura da depressão do eixo sobre a qual a esfera fica apoiada.

\section{Aplicação a materiais cerâmicos}

$\mathrm{O}$ equipamento descrito neste artigo foi aplicado 
na determinação da resistência ao desgaste de amostras de alumina e zircônia parcialmente estabilizada (3Y-PSZ) e, também, de uma amostra da mesma zircônia carbonetada termicamente em atmosfera de argônio. O objetivo da carbonetação é aumentar a resistência ao desgaste e a dureza superficial da zircônia, mantendo a elevada tenacidade à fratura do substrato. A seleção de materiais teve dois critérios: primeiro, usou-se amostras de alumina já estudadas previamente com um equipamento comercial, de modo a permitir a validação dos resultados obtidos com o equipamento descrito neste artigo. Segundo, escolheu-se uma amostra de zircônia que permitiu evidenciar o efeito da carbonetação da superfície sobre a resistência ao desgaste. Nestes ensaios usamos uma esfera de aço endurecido com uma polegada de diâmetro e a largura da depressão do eixo sobre a qual a esfera foi apoiada era de $8 \mathrm{~mm}$. A rotação do eixo foi fixada em $200 \mathrm{rpm}$ e a duração do ensaio foi variada, aumentado a cada medida a distância percorrida pela esfera sobre a amostra. Como se trata de um ensaio comparativo, é fundamental que se mantenham constantes os parâmetros do ensaio para todas as amostras. $\mathrm{O}$ ensaio de microabrasão indica o quanto um material é mais resistente ao desgaste do que outro, nas mesmas condições de análise. Quanto menor o coeficiente de desgaste, mais resistente à abrasão é o material.

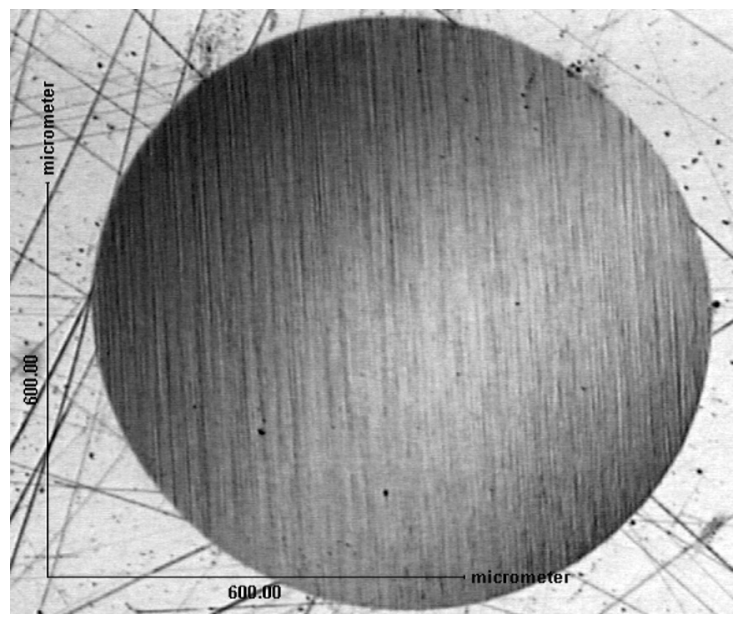

Figura 7: Cratera obtida em ensaio de resistência ao desgaste de uma amostra de $\mathrm{ZrO}_{2} 3$ Y-PSZ .

[Figure 7: Wear crater obtained in a test with a 3Y-PSZ $\mathrm{ZrO}_{2}$ sample.]

A Fig. 7 exibe a micrografia de uma cratera típica, gerada em um dos ensaios de desgaste com uma amostra de zircônia.

Os resultados dos ensaios de desgaste das amostras de alumina e zircônia 3Y-PSZ (esta última antes e depois da formação do recobrimento de $\mathrm{ZrC}$ ) se encontram resumidos na Fig. 8 e na Tabela I. O coeficiente de desgaste determinado para a alumina é similar ao obtido em um trabalho anterior, usando outro abrasivo ( $\mathrm{SiC}$ ) e um equipamento comercial [13]. A amostra de zircônia carbonetada, cuja superfície é constituída essencialmente de $\mathrm{ZrC}$ [12] exibe um coeficiente de desgaste inferior ao da zircônia, sendo tão resistente ao desgaste quanto a alumina testada neste trabalho. Medidas de dureza feitas na superfície da zircônia recoberta com $\mathrm{ZrC}$ demonstraram a ausência de trincas nos vértices das impressões Vickers e constituem um indicativo de que a tenacidade à fratura da zircônia 3Y-PSZ não foi significativamente alterada com a carbonetação da superfície [12].

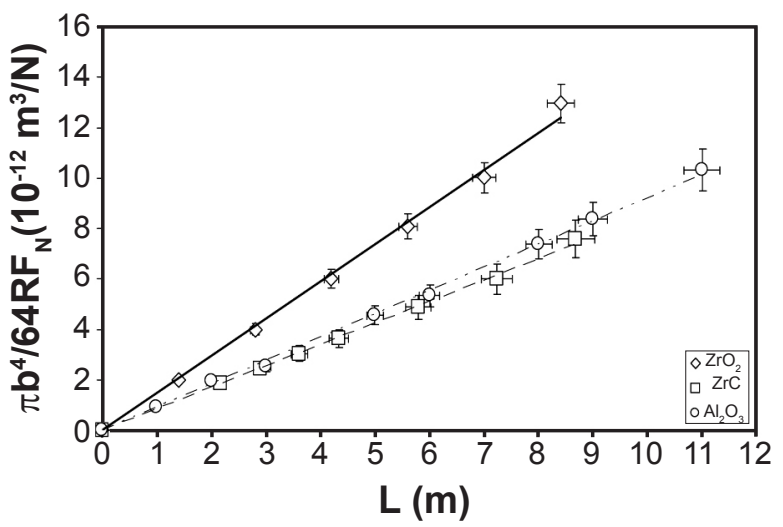

Figura 8: Resultados dos ensaios de desgaste da alumina ( $\square$ ) e da zircônia antes $(\diamond)$ e depois do tratamento térmico em leito de carbono ( $\square$ ).

[Figure 8: Wear test results for alumina $(\square)$ and zirconia before $(\diamond)$ and after thermal treatment in a carbon powder bed $(\square)$.

Tabela I - Coeficiente de desgaste das amostras de alumina e zircônia parcialmente estabilizada com ítria, antes $\left(\mathrm{ZrO}_{2}\right.$ 3 Y-PSZ) e depois $\left(\mathrm{ZrO}_{2} 3 \mathrm{Y}-\mathrm{PSZ}+\mathrm{C}\right)$ do tratamento térmico em leito de carbono. O número entre parênteses representa a incerteza na última decimal.

[Table I - Wear coefficient of alumina and yttria-partially stabilized zirconia samples, before (3Y-PSZ $\mathrm{ZrO}$ ) and after (3Y-PSZ $\left.\mathrm{ZrO}_{2}+C\right)$ thermal treatment in a carbon powder bed. The figure in parenthesis represents the uncertainty in the last decimal.]

\begin{tabular}{cc}
\hline Amostra & $\begin{array}{r}\text { Coeficiente de desgaste } \\
\left(10^{-12} \mathrm{~m}^{2} \mathrm{~N}^{-1}\right)\end{array}$ \\
\hline $\mathrm{Al}_{2} \mathrm{O}_{3}$ & $0,91(5)$ \\
$\mathrm{ZrO}_{2}(3 \mathrm{Y}-\mathrm{PSZ})$ & $1,35(5)$ \\
$\mathrm{ZrC}\left(\mathrm{ZrO}_{2}\right.$ 3Y-PSZ $\left.+\mathrm{C}\right)$ & $0,91(5)$ \\
\hline
\end{tabular}

\section{CONCLUSÕES}

Um equipamento para a medição da espessura de filmes foi adaptado para a medição do coeficiente de desgaste de materiais cerâmicos. Os resultados obtidos em ensaios com amostras de alumina foram similares aos obtidos anteriormente com um equipamento comercial [13]. Os resultados obtidos com a amostra de zircônia recoberta com $\mathrm{ZrC}$ mostraram um aumento na resistência ao desgaste em cerca de 50\% em comparação com a amostra de zircônia 3Y-PSZ original, sem diminuição aparente da 
tenacidade à fratura. Este resultado sugere a possibilidade da obtenção de amostras de zircônia de elevada tenacidade e maior resistência ao desgaste mediante a formação de um recobrimento de $\mathrm{ZrC}$ por meio de tratamento térmico em leito de carbono.

\section{AGRADECIMENTOS}

Este trabalho foi parcialmente financiado por FAPERGS, CAPES e CNPq. Agradecemos a empresa Jacotrade, SP, pela doação da alumina. Agradecemos também ao Laboratório de Altas Pressões e Materiais Avançados do IF/UFRGS pelo uso do forno Thermal. Um agradecimento especial para Águeda Turatti, pelo auxílio na operação do forno Thermal e ao estudante Gustavo R. Ramos pelo auxílio prestado.

\section{REFERÊNCIAS}

[1] Disponível em: http://www.stinstruments.com/Brochures/ Calotest.pdf, acesso em 2/07/2009.

[2] Disponível em: http://www.stinstruments.com/Brochures/ Calowear.pdf, acesso em 2/7/2009.

[3] K. L. Rutherford, I. M. Hutchings, Surf. Coat. Technol. 79 (1996) 231-239.
[4] M. G. Gee, A. J. Gant, I. M. Hutchings, R. Bethke, K. Schiffman, K. Van Acker, S. Poulat, Y. Gachon, J. von Stebut, Wear 255 (2003) 1-13.

[5] Y. Kusano, K. Van Acker, I. M. Hutchings, Surf. Coat. Technol. 183 (2004) 312-327.

[6] M. G. Gee, Wear 259 (2005) 1448-1452.

[7] M. G. Gee, A. J. Gant, I. M. Hutchings, Y. Kusano, K. Schiffman, K. Van Acker, S. Poulat, Y. Gachon, J. von Stebut, P. Hatto, G. Plint, Wear 259 (2005) 27-35.

[8] Disponível em: http://www.weightech.com.br/PDF/ pw4mc3.pdf, acesso em 20/07/2009.

[9] Disponível em: http://www.datasheetcatalog.org/ datasheet/texasinstruments/ina125.pdf, acesso em 20/07/2009.

[10] Disponível em: http://www.provitec.com.br/pdf/ DM\%205000-\%20AXD-MTD,\%2011-07.pdf, acesso em 20/07/2009.

[11] D. R. Lide (Ed.), Handbook of Chemistry and Physics, $85^{\text {th }}$ Ed., CRC Press (2004-2005) 14-12.

[12] J. E. Zorzi, R. Milani, R. F. de L. Lorenzi, C. L. G. de Amorim, C. A. Perottoni, Anais $11^{\text {th }}$ Int. Conf. Adv. Mater., ICAM e VIII SBPMat, Rio de Janeiro, RJ (2009) R538.

[13] J. Catafesta, R. Andreola, C. A. Perottoni, J. E. Zorzi, Cerâmica 53, 325 (2007) 29-34.

(Rec. 29/07/2009, Rev. 30/09/2009, Ac. 25/11/2009) 


\section{Errata}

Cerâmica 56, 340 (2010) 315-319

Adaptação de um equipamento para ensaios de desgaste de materiais cerâmicos (Experimental setup for wear testing of ceramic materials)

R. F. de L. Lorenzi, C. A. Perottoni, J. E. Zorzi

A equação (B) da página 317 é:

$$
g\left(\mathrm{~m} / \mathrm{s}^{2}\right)=9,780356\left(1+0,0052885 \operatorname{sen}^{2} \theta-0,0000059 \operatorname{sen}^{2} 2 \theta\right)-0,003086 H
$$

na qual $g$ é a aceleração da gravidade, $H$ é a altitude $(\mathrm{em} \mathrm{km})$ e $\theta$ é a latitude [11]. A aceleração da gravidade calculada para Caxias do Sul é $9,789 \mathrm{~m} / \mathrm{s}^{2}$.

Cerâmica 59, 352 (2013) 563-569

O título correto do artigo é:

Produção de zeólita analcima a partir de caulim amazônico

(Analcime zeolite production from amazon kaolin)

C. G. Moraes, E. C. Rodrigues, R. S. Angélica, E. N. Macêdo, R. F. Neves 